\title{
A POLÍTICA DE MORTE NA PERIFERIA DA GOVERNAMENTALIDADE NEOLIBERAL
}

\author{
LA POLÍTICA DE MUERTE EN LA PERIFERIA DE LA GUBERNAMENTALIDAD NEOLIBERAL
}

Adriano Negris*

\section{RESUMO}

O presente artigo tem o objetivo de apresentar a relação entre necropolítica e neoliberalismo. Para cumprir a tarefa proposta, tomaremos como fio condutor a noção de governamentalidade neoliberal concebida por Michel Foucault. No estudo sobre a biopolítica Foucault se depara com o problema da população e as formas de governo. Para tratar o tema, Foucault apresenta o conceito de governamentalidade e suas modificações históricas. É nesse contexto de surgem as formas modernas de governamentalidade: o liberalismo e o neoliberalismo. A partir desse ponto da racionalidade governamental moderna, pretendemos demonstrar como a ideia de necropolítica pensada pelo filósofo Achille Mbembe pode se refletir no contexto do neoliberalismo. Nesse sentido, veremos que se por um lado a governamentalidade neoliberal torna-se a grade interpretativa para leitura da biopolítica, por outro lado para a leitura atual do neoliberalismo é imprescindível a compreensão de uma política de morte que se articula em sua periferia.

PALAVRAS-CHAVE: Política. Economia. Neoliberalismo. Biopolítica. Necropolítica.

\section{RESUMEN}

Este artículo tiene como objetivo presentar la relación entre necropolítica y neoliberalismo. Para cumplir con la tarea propuesta, tomaremos como hilo conductor la noción de gubernamentalidad neoliberal concebida por Michel Foucault. En el estudio de la biopolítica, Foucault enfrenta el problema de la población y las formas de gobierno. Para abordar el tema, Foucault presenta el concepto de gubernamentalidad y sus modificaciones históricas. Es en este contexto que surgieron las formas modernas de gubernamentalidad: liberalismo y neoliberalismo. Desde este punto de racionalidad gubernamental moderna, pretendemos demostrar cómo la idea de necropolítica pensada por el filósofo Achille Mbembe puede reflejarse en el contexto del neoliberalismo. En este sentido, veremos que si, por un lado, la gubernamentalidad neoliberal se convierte en la grilla interpretativa para leer la biopolítica, por otro lado, para la lectura actual del neoliberalismo es esencial comprender una política de muerte que se articula en su periferia.

PALABRAS-CLAVE: Política. Economía. Neoliberalismo. Biopolítica. Necropolítica.

\footnotetext{
* Pós-doutorando pela Universidade Federal de Ouro Preto - UFOP. Doutor em Filosofia pela UERJ. E-mail: adrianonegris@gmail.com.
} 


\section{INTRODUÇÃO}

Traçar uma linha de pesquisa a partir da obra de Michel Foucault é tarefa que exige do pesquisador bastante acuidade. Essa dificuldade não é sem fundamento. Ao longo da sua trajetória, falando de maneira panorâmica, Foucault se dedicou basicamente ao estudo de três formas de objetivação pelas quais os seres humanos se tornam sujeitos ${ }^{1}$. Essas formas se dão pelo discurso, pelos modos de clivagem entre os indivíduos ou pelas formas de subjetivação. Essas técnicas de objetivação exigiram de Foucault a elaboração de "ferramentas metodológicas", que ganharam corpo por meio da arqueologia (década de 60) e posteriormente pela genealogia (década de 70), mas que sempre se articularam, principalmente na última fase de seus escritos (década de 80). Para tratar desses "objetos epistemológicos", além de produzir uma vasta literatura, Foucault realizou diversos desvios em seus estudos. Por tudo isso é sempre um empreendimento árduo elaborar uma pesquisa mais "linear" sobre a obra do pensador francês.

Apontados esses obstáculos, o presente trabalho tem o objetivo precípuo de apresentar a relação entre o neoliberalismo e a necropolítica. Elegemos como fio condutor de nossa abordagem a análise feita por Foucault sobre o neoliberalismo no Curso Nascimento da biopolítica (1979). Dada a impossibilidade de aprofundamento sobre os temas ventilados nesse curso, realizamos um recorte de modo a tratar diretamente do neoliberalismo, tal como visto em Nascimento da biopolitica. Sabemos dos riscos de tal atitude e por essa razão tentaremos situar o leitor quanto a alguns conceitos do vocabulário foucaultiano que possam estar correlacionados com a compreensão do neoliberalismo.

Iniciaremos nosso texto apontando as principais linhas de construção do neoliberalismo em Foucault. Veremos que esse tema aparece devido à necessidade de melhor esclarecer os desdobramentos da biopolítica, a qual vinha sendo tematizada desde o texto $O$ nascimento da medicina social (1974), passando por Vigiar e punir (1975), Em defesa da sociedade (1976), História da sexualidade (1976) e Segurança, território e população (1978).

Veremos, ainda, que o (neo)liberalismo transforma-se para Foucault em uma grade interpretativa por meio da qual o fenômeno da biopolítica deve ser abordado. Obviamente o neoliberalismo já passou por diversas mutações e não cabe aqui enumerá-las. Entretanto, para

\footnotetext{
${ }^{1}$ Em um texto do ano de 1982 - O sujeito e o poder - Foucault (2009) diz expressamente que seu objetivo durante vinte anos de pesquisa foi criar uma história dos diferentes modos de subjetivação dos seres humanos em nossa cultura. Para isso, afirma Foucault, foi necessário investigar três modos de objetivação que tornam os seres humanos sujeitos.
} 
os fins deste trabalho, vamos tomar as lições de Foucault em Nascimento da biopolítica (2008a) e considerar que para pensar a biopolítica é necessário que esse gesto seja feito através da governamentalidade neoliberal. Por esse motivo passaremos em revista o essencial do liberalismo para alcançar com mais precisão o neoliberalismo visto por Foucault.

Dito isso, defenderemos a posição de que a biopolítica não é a única forma de poder que atua no sistema de governo neoliberal. Em conjugação com a biopolítica surge uma forma de poder que centraliza seus cálculos para a produção de morte, o que o filósofo camaronês Achille Mbembe chamou de necropolítica. Sustentamos, em última análise, que a necropolítica é um fenômeno paralelo e distinto da biopolítica e que ganha sua forma na periferia do neoliberalismo.

\section{FOUCAULT E O NEOLIBERALISMO}

O primeiro ponto que tentaremos esclarecer é como o neoliberalismo surge como um tema ligado à biopolítica. Começamos nossa linha de interpretação situando o leitor no contexto genealógico (escritos dos anos 1970), em que Foucault prioriza a pesquisa sobre a formação efetiva dos discursos para, em seguida, se voltar para a analítica das relações de poder.

É por meio desses estudos que Foucault identificará na biopolítica uma forma de poder que atua sobre a vida dos indivíduos. Através de técnicas disciplinares a biopolítica torna os corpos produtivos e politicamente mais débeis. De outro lado, essa mesma biopolítica estará voltada para o controle da população (um corpo-espécie), centrada no controle da vida do homem enquanto espécie. Sob essa perspectiva o biopoder intervém a partir dos dispositivos de segurança ${ }^{2}$, programados para normalizar e afastar os riscos ou perigos que eventualmente possam prejudicar a "saúde" da população. A função geral da biopolítica, sob esse último aspecto, é mover as relações de poder no sentido de "fazer viver e deixar morrer".

\footnotetext{
${ }^{2}$ Michel Foucault explica que os dispositivos de segurança inserem os fenômenos aleatórios da população (por exemplo, o roubo) no registro de probabilidade. As reações do poder ante esse fenômeno vão ser abalizadas mediante um cálculo, levando em consideração a relação custo-benefício. Por último, os dispositivos de segurança vão estabelecer uma média considerada ótima e, depois, fixar os limites do que viria a ser uma conduta aceitável. Edgardo Castro comenta que "os dispositivos de segurança se ocupam, em resumo, de fenômenos de massa, em série, de longa duração. Daí a importância que, no desenvolvimento desses dispositivos, teve o que no século XVIII se denominava ciência da polícia, vale dizer, a estatística. Então, na medida em que se trata de administrar esse conjunto e seus efeitos, os dispositivos de segurança devem funcionar tendo em conta a aleatoriedade dos acontecimentos futuros" (CASTRO, 2015, p. 111).
} 
O Curso Segurança, território e população, seguindo na esteira do curso de $1976^{3}$, visava inicialmente construir uma "história dos dispositivos de segurança". Ao longo da elaboração desse discurso histórico, Foucault percebeu a presença de um elemento da biopolítica que se mostrava mais problemático: o conceito de população. É a partir do caráter histórico dos dispositivos de segurança que Foucault nota a emergência de um novo objeto (a população) digno de maior atenção. Assim, Foucault procede o deslocamento da proposta inicial e o conceito de população ganha centralidade no curso de 1978.

$\mathrm{O}$ aprofundamento quanto à questão da população abre como correlato o horizonte para o entendimento da arte de governar ${ }^{4}$. Sobre esse novo ponto, Foucault compreende que as técnicas de controle da população estão mais afinadas com a ideia de governo do que com o exercício da soberania. Nessa passagem do regime de soberania para um regime dominado pelas técnicas do governo podemos ver o aparecimento de um novo tipo de saber, a economia política (FOUCAULT, 2008b, p. 141).

$\mathrm{Na}$ aula de $1^{\circ}$ de fevereiro de 1978 , Foucault começa a tratar da questão do governo e apresenta o conceito de "governamentalidade" ${ }^{5}$. O conceito de governo ${ }^{6}$ tem o sentido de "arte de exercer o poder na forma da economia". A gorvenamentalidade reflete o conjunto de

\footnotetext{
${ }^{3}$ No curso de 1976 Foucault já havia apresentado os três grandes domínios de intervenção da biopolítica: os processos de natalidade e mortalidade, o que trouxe uma outra perspectiva sobre o problema da morbidade; os fenômenos da velhice, dos acidentes e doenças. Em suma, todos os acontecimentos que afetam a capacidade dos indivíduos; a relação dos homens com o seu meio, visto, principalmente, por meio do problema das cidades.

${ }^{4} \mathrm{O}$ fator que mais contribuiu para o avanço da arte de governo foi o problema da população. De três modos o problema da população ajudou a liberar o desenvolvimento da arte de governo. O primeiro: a população deslocou a noção de economia, que deixou de se pautar no modelo da família para focar seus esforços nos fenômenos atinentes à realidade da população. $\mathrm{O}$ segundo modo de contribuição: a população se mostrará como o objetivo final do governo. Ao governo cabe melhorar a sorte da população, fomentar as riquezas, aumentar a duração de vida da população, sua saúde e higiene. Para agir em prol da população, o governo irá usá-la como instrumento para a consecução de seus fins. Por último, uma vez que a população vira objeto de governo, ela igualmente se torna o suporte para a formação de saberes para um modo racional e planejado de governo. Dessa maneira, vemos que um saber de governo está disposto de forma indissociável de um saber sobre a população, o que num sentido mais amplo denominamos de economia. No procedimento de aprendizagem acerca dos processos ligados à população é que se formará uma ciência chamada de economia política.

${ }_{5}^{5}$ Sobre o termo governamentalidade, a partir de 1978, em seu curso no Collège de France, Foucault analisa a ruptura que se produziu entre o final do século XVI e o início do século XVII e que marca a passagem de uma arte de governar herdada da Idade Média, cujos princípios retomam as virtudes morais tradicionais (sabedoria, justiça, respeito a Deus) e o ideal de medida (prudência, reflexão), para uma arte de governar cuja racionalidade tem por princípio e campo de aplicação o funcionamento do Estado: a "governamentalidade" racional do Estado. Essa "razão do Estado" não é entendida como a suspensão imperativa das regras pré-existentes, mas como uma nova matriz de racionalidade que não tem a ver nem com o soberano de justiça, nem com o modelo maquiavélico do Príncipe. A razão de Estado marca a ideia de que as regras, técnicas e saberes para a condução do Estado são produzidas no interior do funcionamento do Estado, sem recorrer a princípios que transcendem a sua ordem. Ao regime de regularidade e positividade das regras, técnicas e saberes voltados para a arte de governar Foucault chamou de governamentalidade.

${ }^{6} \mathrm{O}$ governo pode ser traduzido como o exercício do poder que consiste em "conduzir condutas" e em ordenar a probabilidade. Governar, nesse sentido, é estruturar o eventual campo de ação dos outros (FOUCAULT, 2014b, p. 133-134).
} 
tecnologias destinadas a exercer o poder sobre a população, tendo a economia política como saber central, tendo as leis, as disciplinas e os dispositivos de segurança como instrumentos tecnológicos (FOUCAULT, 2008b, p. 143-144).

Quanto ao processo histórico da gorvenamentalidade, Foucault destaca que no século XVIII ela sofre uma alteração fundamental e passa a limitar os poderes do Estado. O saber da economia política possibilita a criação de uma nova racionalidade na arte de governar: governar menos para ter eficiência máxima em função da naturalidade dos fenômenos econômicos. Com essa nova racionalidade compreende-se que os processos econômicos são regidos por leis internas e não por paradigmas externos. É essa governamentalidade, essencialmente ligada ao esforço de autolimitação do governo, que Foucault chama de "liberalismo" (SENELLART apud FOUCAULT, 2008b, p. 523).

Foucault vê no liberalismo mais uma prática de governo do que uma teoria econômica ou jurídica. Como racionalidade governamental o liberalismo não corresponde exatamente a doutrinas nas quais a liberdade é o conceito-chave. Na concepção de Foucault o liberalismo deve ser visto como o exercício máximo de um tipo de racionalidade política (BONNAFOUS-BOUCHER, 2001, p. 40). O liberalismo visa atender às regras de economia máxima, porém, não no sentido de se governar o máximo possível com o menor custo, mas no sentido em que se pergunta se não é mais custoso governar do que não governar. Foucault vê o liberalismo como racionalidade política $\mathrm{crítica}^{7}$, no sentido de se perguntar constantemente sobre seus limites de atuação, até aonde é possível governar. Por isso, para Foucault, o liberalismo é uma forma de reflexão crítica sobre a razão governamental.

A razão governamental do liberalismo terá que lidar com dois tipos de interesses que se encontram em jogo na sociedade: de um lado o interesse na troca de riquezas e, de outro, a utilidade e jurisdição interna do poder público. Pode-se dizer que o liberalismo é uma razão manipuladora e reguladora de interesses. Assim sendo, o mercado e a totalidade dos processos econômicos tornam-se o "lugar" de produção e gestão de liberdade: liberdade de mercado, liberdade de compra e venda, liberdade de expressão etc. A razão governamental do liberalismo não é caracterizada por ser uma simples garantidora dessas liberdades, mas sim por ser uma consumidora de liberdade. E ela é consumidora porque a liberdade individual não

\footnotetext{
${ }^{7}$ Nesse sentido a economia política é um saber essencial para notabilizar o liberalismo como uma racionalidade crítica. A economia política representa uma análise da produção e da circulação das riquezas, com vistas a assegurar a prosperidade do Estado. Mais que isso, a economia política é uma reflexão acerca da organização, limites e dos poderes da sociedade. Assim, para Foucault, a economia política é um marco fundamental para que a autolimitação da razão governamental se torne uma realidade (FOUCAULT, 2008a, p. 18).
} 
é dada; para que ela exista é imprescindível o gerenciamento governamental ${ }^{8}$. O uso do termo liberalismo em Foucault se justifica porque a liberdade é fundamento da arte liberal de governar: "liberdade garantida, sem dúvidas, mas também produzida por essa arte, que para alcançar seus fins necessita suscitá-la, mantê-la e enquadrá-la permanentemente" (SENELLART apud FOUCAULT, 2008a, p. 444). Sendo assim, a liberdade não é exercida irrestritamente, pois ela é regulada por um princípio de cálculo: os dispositivos de segurança, que são o outro lado e a condição de existência do governo liberal (LEMKE, 2017, p. 67).

Conforme se pode notar, o liberalismo assume grande protagonismo na história da governamentalidade, até mesmo porque ele é justificado como horizonte interpretativo da biopolítica $^{9}$. Já os estudos sobre o neoliberalismo surgem porque é preciso investigar as sucessivas crises de governamentalidade que o sistema liberal $\operatorname{suscita}^{10}$. O conflito entre a administração de interesses individuais e a segurança da sociedade conduz o liberalismo a crises sistemáticas. Nesse sentido o neoliberalismo aparece como resposta às atribulações internas do liberalismo.

No curso Nascimento da biopolítica Foucault realiza uma análise das governamentalidades críticas que moldaram as diferentes correntes neoliberais do século XX. Tanto o neoliberalismo alemão da Escola de Friburgo (ordoliberalismo) quanto o neoliberalismo americano da Escola de Chicago são respostas críticas, ou seja, limites à propensão ao excesso de governo que o liberalismo autoriza ${ }^{11}$. Veremos adiante os traços mais marcantes do neoliberalismo enquanto racionalidade governamental crítica.

\footnotetext{
${ }^{8}$ Como explica Foucault, o liberalismo é uma arte governamental que consome liberdade e, se é assim, então ela é obrigada a fabricar liberdade a cada momento e a organizar toda essa liberdade que circula na sociedade.

${ }^{9}$ Conforme explica Lemke (2017, p. 63): “[...] conceitos liberais de autonomia e liberdade estão intimamente conectados às noções biológicas de autorregulamentação e autopreservação, que prevalecem sobre o paradigma mecanicista de investigação dos corpos, dominante até então."

${ }^{10}$ Uma das dinâmicas na qual o liberalismo se vê envolvido é a administração de interesses. Assim, essa arte liberal de governar tem a tarefa de supervisionar os diferentes interesses individuais que podem oferecer um risco ao interesse coletivo. De outro lado, também será necessário proteger os interesses individuais contra tudo o que puder se revelar, em relação a eles, como um abuso vindo do interesse coletivo (FOUCAULT, $2008 \mathrm{a}, \mathrm{p}$. 89). O liberalismo produz liberdade e com isso gera igualmente toda uma gama de interesses (individuais e coletivos) que deve administrar. Ao manipular esse jogo de interesses, o liberalismo também é obrigado a gerenciar os perigos que assolam os interesses que circulam na sociedade. Esses perigos têm seus efeitos anulados ou reduzidos pelos dispositivos de segurança.

11 O plano econômico New Deal é um dos exemplos de excesso de governo. A política do New Deal implementada pelo presidente norte-americano Franklin Roosevelt em 1932 é um exemplo a ser citado. Grosso modo, o New Deal foi um pacote de medidas de forte cunho intervencionista destinado a recuperar a economia norte-americana após a crise de 1929. O pacote era uma forma de garantir mais liberdade (liberdade de trabalho, liberdade de emprego, liberdade de consumo, liberdade política) numa situação de perigo. Esse incremento na produção de liberdade veio ao custo de uma série de intervenções diretas no mercado e na economia em geral. Dado esse "paradoxo", Senellart (apud FOUCAULT, 2008a, p. 444) acentua que "os procedimentos de controle e as formas de intervenção estatal requeridos por essa dupla exigência (liberdade e segurança) é que constituem o
} 
Quando Foucault observa a sociedade sob a perspectiva da governamentalidade neoliberal, tal como no liberalismo, ele vê uma pluralidade de interesses em jogo, de modo que os interesses particulares devem ser equacionados para que não prejudiquem o interesse coletivo e vice-versa. A dinâmica dessa relação exige que haja um espaço para a diversidade, considerando as diferenças dos indivíduos e as práticas minoritárias (aqui deve ficar claro que não se está insinuando que o neoliberalismo tende a proteger o interesse das minorias).

$\mathrm{Na}$ verdade, o sistema neoliberal anseia sempre a inclusão, porém, de outro lado, exige a preservação da forma concorrencial. Para isso se sustentar, a desigualdade é um dos eixos centrais dessa forma de governo. Sobre a sociedade neoliberal Foucault (2008a, p. 354-355) diz que o

\begin{abstract}
que aparece não é em absoluto o ideal ou o projeto de uma sociedade exaustivamente disciplinar em que a rede legal que encerra os indivíduos seria substituída e prolongada de dentro por mecanismos, digamos, normativos. Tampouco é uma sociedade em que o mecanismo da normalização geral e da exclusão do não-normalizável seria requerido. Tem-se, ao contrário, no horizonte disso, a imagem ou a ideia ou tema-programa de uma sociedade na qual haveria otimização dos sistemas de diferença, em que o terreno ficaria livre para os processos oscilatórios, em que haveria uma tolerância concedida aos indivíduos e às práticas minoritárias, na qual haveria uma ação, não sobre os jogadores do jogo, mas sobre as regras do jogo, e, enfim, na qual haveria uma intervenção que não seria do tipo da sujeição interna dos indivíduos, mas uma intervenção de tipo ambiental.
\end{abstract}

A otimização dos sistemas de diferença que Foucault nos fala é essencial para a manutenção da lógica expansionista do mercado e para a concorrência (obviamente devemos considerar o termo "diferença" no contexto neoliberal como um eufemismo para desigualdade). O neoliberalismo dispõe a sociedade segundo a pluralidade e, por essa razão, a sociedade neoliberal não pode ser uma sociedade unificada ou totalizada em torno de um ideal ou valor. A sociedade neoliberal não é massificada, mas sim plural e ao mesmo tempo desigual. Por essa razão Lagasnerie (2013, p. 89) diz que

\begin{abstract}
Não é difícil imaginar um mundo fundamentalmente plural, que permita a expressão dos diversos modos de existência e contradições em vez de querer reprimi-las. E é precisamente nessa ótica que se inscreve a utopia de uma "mercadização" da sociedade: com efeito, o mercado é aqui concebido como a instância que permite o desenvolvimento de uma "ordem espontânea que deixa os indivíduos livres para utilizar seu próprio conhecimento visando a seus próprios objetivos". O mercado não é uma organização. Não se funda em uma ideia de harmonia, unidade ou coerência. É aberto à heterogeneidade.
\end{abstract}

paradoxo do liberalismo e estão na origem das 'crises de governamentalidade' que ele vem conhecendo há mais de dois séculos". 
Como Lagasnerie expõe, o mercado é uma instância que permite o desenvolvimento de uma ordem espontânea e que deixa os indivíduos livres para a consecução dos seus próprios objetivos. A sociedade por completo assume a forma-mercado. Ela se torna um espaço aberto, heterogêneo, cuja função do governo é de otimização dos sistemas de diferença, deixando a sociedade livre para os processos oscilatórios. Desse modo, há sempre o espaço de liberdade para os indivíduos perseguirem seus interesses, inclusive os interesses que movem as práticas minoritárias. Entretanto, é sempre bom lembrar o "outro lado dessa história": nessa sociedade a tolerância para as práticas minoritárias está submissa à lógica "mercadológica". Tudo deve ser englobado por essa sociedade e gerenciado racionalmente em termos de custo-benefício ${ }^{12}$.

Uma vez que se trata de uma sociedade composta de subjetividades moleculares, agindo conforme seus interesses e num espaço de liberdade, a racionalidade de governo passa a ser a modulação desses fluxos moleculares. A modulação representa uma espécie de técnica que pode acompanhar ou incorporar a subjetividade neoliberal, moldando-a e deformando-a, a todo o tempo e em qualquer lugar. Ela acompanha todo o fluxo de variação molecular dos indivíduos, tais como afetos, desejos, memória, libido, etc.

Em nossa sociedade contemporânea a arte de governo neoliberal não atua exclusivamente para organizar os indivíduos através dos grandes meios de confinamento (escola, quarteis, hospitais, prisão), nem opera somente com a finalidade de normalização da população. A tecnologia neoliberal cuida da vida ao nível molecular, não tentando organizar e unificar a multiplicidade, mas sim criando um ambiente para a produção dessas novas subjetividades. Essa arte de governar, como disse Foucault, não visa regular os sujeitos, ela intervém no ambiente criado alterando "as regras do jogo", deixando os jogadores livres. Trata-se, como Foucault mesmo disse, de uma intervenção ambiental.

O "ambiente" neoliberal possui como "tema-programa" a condução dos indivíduos no sentido de que todos podem e devem incrementar o capital humano ${ }^{13}$, segundo a ordem do

12 Assim, por exemplo, não há propósito de acabar com a criminalidade, pois isso denotaria custos extraordinários, com a incerteza de resultados eficazes. Então, deve-se manter e gerenciar a criminalidade em um patamar aceitável. Dessa mesma forma, deve-se gerenciar e tolerar a pobreza, a fome, e em última instância, as mais diversas situações que levam à degradação do ser humano.

${ }^{13}$ Theodore William Schultz, economista norte-americano, prêmio Nobel de Ciências Econômicas, colaborador da Escola de Chicago e idealizador da Teoria do Capital Humano. Gary Stanley Becker economista estadunidense, prêmio Nobel de Ciências Econômicas, colaborador da Escola de Chicago. Becker deu prosseguimento aos estudos sobre a Teoria do Capital Humano, analisando, principalmente, o custo-benefício das atividades que aumentam a produtividade. Foucault, acompanhando as reflexões de Gary Becker, explica que o capital humano compreende o conjunto de aptidões e habilidades (naturais ou adquiridas) do indivíduo que o capacitam a auferir uma renda. Esse conjunto de competências que é o capital pode ser traduzido como uma 
empreendimento. A atmosfera neoliberal "encoraja os indivíduos a dar à suas vidas uma forma específica: a empreendedora" (LEMKE, 2017, p. 124). É preciso fabricar liberdade para que as subjetividades possam ser constituídas pelo empreendimento livre de si mesmo, adquirindo novas competências (materiais e imateriais) para agregar ao capital humano. Dentro dessa lógica empresarial que toma conta da vida, a pluralidade e o empreendedorismo tornam-se um corolário dessa sociedade. No entanto, essa forma de governo leva a produzir profundas segmentações sociais, étnicas, etárias, culturais e identitárias (apenas para dar alguns exemplos $)^{14}$. Tais clivagens interagem entre em si num regime de competição, “exaltando a rivalidade como emulação motivadora” (TÓTORA, 2011, p. 97).

No neoliberalismo novos saberes surgem em detrimento de saberes que outrora eram utilizados para a gestão biopolítica da população, tais como a estatística e a demografia. Agora os novos saberes correspondem à nova forma de governamentalidade. Assume destaque no cenário contemporâneo a informática, a cibernética, a nanotecnologia, a comunicação, o marketing, a publicidade, a genética, a farmacologia. Todos esses novos saberes contribuem para a formação de novos jogos de verdade e práticas discursivas e não discursivas, bem como para a constituição das novas subjetividades exigidas pela era neoliberal.

Em um texto denominado Foucault: biopolítica e governamentalidade neoliberal, a autora Silvana Tótora expõe de forma esclarecedora como a técnica de governo neoliberal deslocou a maneira de operar do sistema capitalista. Observe-se:

O capitalismo globalizado com base nos fluxos financeiros e privilegiando o
consumo material e imaterial em detrimento da produção dissemina por todo o corpo
social o modelo da empresa redefinindo os espaços políticos, os corpos, as
populações e as subjetividades. Os corpos disciplinados, moldados em instituições
de sequestro - médicas e educacionais - cedem vez aos corpos de modulações
mutáveis - aqueles que o discurso neoliberal denomina de capital humano - dotados
de flexibilidade, inteligência emocional e habilidades comunicativas consumíveis
em um mercado econômico competitivo. [...] O governo da população enquanto uma
massa normalizável com base numa série aberta de curvas de normalidade cede à

espécie de máquina; mas uma máquina entendida no sentido positivo, pois é uma máquina que produzirá fluxos de renda.

${ }^{14}$ Como aponta o comentador Geoffroy de Lagasnerie, o principal inimigo do neoliberalismo se concretiza a partir de toda a construção de paradigmas dirigistas ou coletivistas. Ao fim e ao cabo, trata-se de uma revolta contra toda concepção totalizante ou tentativa de estabelecer um modelo de fundamento ou metaestrutura para corrigir os sentidos ônticos que nos orientam no mundo. Lagasnerie assim comenta: "o neoliberalismo não cessou de se opor, aquilo contra o que ele se constituiu com mais força e persistência, é uma atitude filosófica mais geral, que vemos vigorando em escolas, países ou períodos distintos, mas que, segundo seus defensores, tem sua verdadeira origem no pensamento iluminista: tal atitude é a que consiste em promover uma percepção unificante ou unificadora da sociedade, valorizando tudo que diz respeito ao 'comum', ao 'coletivo', ao 'geral', em detrimento do que seria da esfera do individual, do particular, do local.” (LAGASNERIE, 2013, p. 65-66). 
uma hierarquia que (in)dividualiza com base em recursos raros inatos da genética ou adquiridos pela formação que produz o empresário de si mesmo ou capital/máquina. Nessa configuração capitalista regida pelos dispositivos de controle, valoriza-se a diversidade e não a homogeneidade massificante do modelo industrial. Na medida em que o trabalho e o trabalhador não mais se separam, pois o trabalho é o próprio capital que produz renda - conforme os discursos neoliberais de verdade - torna-se comum fazer do trabalho fonte de prazer. (TÓTORA, 2011, p. 97).

Todo esse ambiente neoliberal é descrito por Gilles Deleuze no texto Post scriptum sobre a sociedade de controle (1992). Contudo, acreditamos que a denominada sociedade de controle, caracterizada no texto de Deleuze, é um delineamento da atuação dos mecanismos da governamentalidade neoliberal estudada por Foucault em Nascimento da biopolítica. A sociedade de controle deleuziana é uma expressão ou um desenho dos indicativos deixados por Foucault sobre o neoliberalismo.

Com bem traduz Deleuze, a empresa é uma alma (um espírito, um gás, um pneuma, um geist), mas que anima a sociedade e como tal "introduz o tempo todo uma rivalidade inexplicável como sã emulsão, excelente motivação que contrapõe os indivíduos entre si e atravessa cada um, dividindo-o em si mesmo" (DELEUZE, 1992, p. 221). Ora, a transformação da sociedade em mercado, e o regime concorrencial que a acompanha, mistura toda a heterogeneidade que nela existe para colocá-la em um estado constante de tensão, refletido através da lógica concorrencial. Daí Deleuze dizer, com acerto, que nesse tipo de sociedade "nunca se termina nada, a empresa, a formação, o serviço sendo os estados metaestáveis e coexistentes de uma mesma modulação, como que de um deformador universal" (DELEUZE, 1992, p. 221-222).

$\mathrm{Na}$ sociedade de controle descrita por Deleuze a cifra, a informação, tornam os indivíduos "dividuais", divisíveis, e as massas amostras, dados, mercado ou "bancos" (DELEUZE, 1992, p. 222). Nesse contexto ressalta-se a ideia de que o homem se torna uma máquina-fluxo em constante operação e aperfeiçoamento. No entanto, nos parece que o ponto alto da análise do autor de $O$ anti-Édipo aparece quando ele descreve as relações entre o mercado e as novas formas de produção associadas ao capitalismo contemporâneo. Diz o filósofo francês:

Quanto ao mercado, é conquistado ora por especialização, ora por colonização, ora por redução dos custos de produção. Mas atualmente o capitalismo não é mais dirigido para a produção, relegada com frequência à periferia do Terceiro Mundo, mesmo sob as formas complexas do têxtil, da metalurgia ou do petróleo. É um capitalismo de sobreprodução. Não compra mais matéria-prima e já não vende produtos acabados: compra produtos acabados, ou monta peças destacadas. O que ele quer vender são serviços, e o que quer comprar são ações. Já não é um 
capitalismo dirigido para a produção, mas para o produto, isto é, para a venda ou para o mercado. Por isso ele é essencialmente dispersivo, e a fábrica cedeu lugar à empresa. A família, a escola, o exército, a fábrica não são mais espaços analógicos distintos que convergem para um proprietário, Estado ou potência privada, mas são agora figuras cifradas, deformáveis e transformáveis, de uma mesma empresa que só tem gerentes. (DELEUZE, 1992, p. 223-224).

Diante desse diagnóstico que tentamos traçar sobre o nosso presente, podemos dizer, ancorados nas lições deixadas por Foucault, que a governamentalidade neoliberal, pelas suas características, é uma tecnologia de governo que transforma os modelos disciplinar e biopolítico da população, fazendo com que a sociedade como um todo seja compreendida sob a "forma-empresa". Isso faz com que se instaure uma grade de inteligibilidade na qual o mercado e a lógica empresarial passam a ser o locus de veridicção ${ }^{15}$ da sociedade. As subjetividades, nesse caso, são produzidas segundo a forma do capital e, graças aos novos saberes, as técnicas de governo passaram a atuar em nível molecular para criar subjetividades $\operatorname{assujeitadas}^{16}$.

Nessa esfera neoliberal contemporânea os indivíduos devem suprir as condições existenciais básicas (comer, dormir, abrigar-se, descansar) e, além disso, eles são conduzidos a realizar uma constante "capitalização de si mesmos". Dessa maneira, vemos os elementos econômicos colonizarem todos os níveis da existência humana. Os novos saberes, com destaque para a genética, inscrevem a biopolítica em outro registro, deslocando-a e concretizando-a como uma tecnologia de governo que opera junto à camada molecular dos corpos (equipamento genético, hormônios, neurônios e os variados estados psíquicos). A partir daí novas subjetividades são produzidas e moduladas sob a lógica concorrencial do mercado globalizado.

Ainda dentro desse cenário, vemos os antigos dispositivos de segurança da população sendo sistematicamente desmontados. Quando fazemos essa afirmação pensamos nos sistemas de previdência, saúde pública e assistência social ${ }^{17}$. Obviamente tais dispositivos são

\footnotetext{
${ }^{15} \mathrm{O}$ conceito de veridiç̧ão representa o regime de verdade ou conjunto de regras que estabelecem o que pode ser considerado verdadeiro ou falso e os efeitos de poder vinculados ao dizer verdadeiro. No liberalismo o mercado deixa de ser um espaço de jurisdição para se tornar um locus de veridicção (autorregulamentação). É nesse lugar que se legitima ou não as práticas governamentais. No neoliberalismo essa função da veridicção é realizada pelo cálculo dos custos e benefícios da racionalidade empresarial.

${ }^{16} \mathrm{O}$ neoliberalismo dá ênfase à produção de sujeitos ativos, autônomos, calculadores e responsáveis pelo seu próprio sucesso ou fracasso.

${ }^{17}$ Há no neoliberalismo uma transferência de atividades governamentais para atores não estatais. Como explica Thomas Lemke (2017, p. 122), "os estudos de governamentalidade mostram que o assim chamado 'recuo do Estado' é na verdade uma extensão do governo, e que o neoliberalismo não é o fim da política, mas sua transformação que reestrutura as relações de poder na sociedade. Portanto, existe um deslocamento das técnicas formais para técnicas informais de governo".
} 
mecanismos globais que resguardam a normalização da população, afastando ou atenuando os efeitos aleatórios naturais da vida que podem levar ao desiquilíbrio da população. Esses dispositivos geram custos econômicos que usualmente são assumidos pela própria coletividade na forma do Estado. Porém, a forma neoliberal de governo entende que esses dispositivos hoje não se sustentam pois o Estado deve "governar o mínimo possível". Deve-se instaurar um controle racional de governo em que o Estado seja "mínimo". Dessa forma, como modo racional de governo, o Estado não deve custear determinadas políticas públicas, salvo aquelas que sejam essenciais para a manutenção da ordem e da lógica concorrencial do mercado.

Qual a consequência dessa técnica de governo? Primeiramente o desarme de um Estado de bem-estar social, que preza pela efetivação dos direitos fundamentais, bem como aqueles direitos fundamentais considerados de segunda e terceira geração: os direitos sociais e os direitos difusos (meio ambiente, por exemplo). Os sistemas que giravam em torno da ideia de solidariedade, tal como o sistema de previdência, são vilipendiados pela lógica mercadológica e disseminada a ideia de que cada um deve se capitalizar durante a vida para que na velhice possa usufruir da renda capitalizada. E se por um acaso os indivíduos não se ajustarem a esse mecanismo de previdência? Não importa, a desigualdade é um cálculo necessário à sobrevivência do sistema neoliberal. Todos podem ter uma aposentadoria digna custeada com recursos públicos? A resposta dos neoliberais é não. Custear aposentadoria para todos, educação para população, hospitais e saúde para o público em geral, além de ser muito oneroso para o Estado, isso fere a lógica empresarial e concorrencial que tomou conta da sociedade.

O desafio contemporâneo para o governo neoliberal talvez seja encontrar uma maneira mais eficiente de administrar a desigualdade, que é visivelmente crescente nas grandes metrópoles do planeta. Há nas grandes cidades do mundo uma população periferizada, excluída dos processos políticos e sociais. Populações anteriormente consideradas "suspeitas" ou "marginais", hoje são vistas em situação de vulnerabilidade e sujeitas a todo tipo de intervenção com a finalidade de controlar os danos que essas populações podem causar à sociedade. Como afirma Deleuze em Post scriptum sobre a sociedade de controle, o capitalismo manteve na extrema "miséria de três quartos da humanidade, pobres demais para a dívida, numerosos demais para o confinamento: o controle não só terá que enfrentar a dissipação das fronteiras, mas também a explosão dos guetos e das favelas" (DELEUZE, 1992, p. 224). 
O crescimento das populações que vivem nas periferias dos grandes centros urbanos, a constante ameaça do fechamento de fronteiras dos países ricos para proibir a entrada de imigrantes, o aumento do trabalho escravo e degradante, o comércio de pessoas e de órgãos, discriminação étnico-racial e violência policial através do Estado são apenas alguns problemas biopolíticos contemporâneos da era da governamentalidade neoliberal.

E quem dirá que os paradoxos da biopolítica descritos por Foucault no curso Em defesa da sociedade não persistem ainda hoje? O poder atômico, pertencente hoje não só a grandes potências mundiais, mas também a países fora do eixo Europa-EUA, não continua sendo uma manifestação do poder soberano de matar a própria vida? A ameaça de uma epidemia pela fabricação de vírus incontroláveis e universalmente destruidores ainda não continua a assombrar a vida da população mundial? Essa máxima potencialização do biopoder não continua a ultrapassar toda a soberania humana?

A análise contemporânea da biopolítica, como vimos neste tópico, deve ser realizada por meio da tecnologia de governo neoliberal. Isso desloca o registro biopolítico para um novo conjunto de práticas discursivas e não-discursivas que permitem a formação de novos saberes e outras configurações das relações de poder. Nesse novo cenário, saber e poder assumem novas estratégias para a construção de subjetividades. Ou dito de outro modo, a arte de governo neoliberal situa a biopolítica em novos jogos de verdade de relação de si para si e a constituição de si mesmo como sujeito.

\section{NECROPOLÍTICA NA PERIFERIA DO NEOLIBERALISMO}

Vimos que para Foucault o (neo) liberalismo é o tipo de governamentalidade por meio da qual a biopolítica deve ser compreendida. Não obstante, entendemos que no interior do neoliberalismo a biopolítica não é a única forma de controle dos corpos e gestão da população. Defendemos a perspectiva de que em determinadas regiões do globo, principalmente aquelas situadas em países que estão na periferia do processo de globalização do capital, há outras relações de poder que atuam sobre a população e que convivem em tensão ou em paralelo com a biopolítica. Essa outra forma de poder é chamada por Achille Mbembe de necropolítica.

O ensaio de Mbembe, chamado Necropolítica (2018), pode ser descrito como um texto que tem a morte como um mecanismo central operando dentro da política global. Mbembe 
mobiliza um número de ideias para demonstrar como a necropolítica reconfigura as relações sociais, apagando as fronteiras entre a resistência e o suicídio, o sacrifício e a redenção, o martírio e a liberdade. Ademais, Mbembe considera a necropolítica uma importante ferramenta analítica, uma vez que a biopolítica não seria o paradigma de análise mais adequado para explicitar determinadas relações de poder que se desdobram em certas regiões do globo ${ }^{18}$.

O que seria propriamente a necropolítica ${ }^{19}$ ? Mbembe explica a necropolítica com base em três conceitos: a noção de biopoder foucaultiana, os conceitos de soberania e de estado de exceção ${ }^{20}$. Essas categorias são destinadas a pensar não a ideia de soberania como autonomia

\begin{abstract}
${ }^{18}$ Mbembe inicia seu texto colocando em questão a biopolítica de Foucault como ferramenta eficaz de análise das relações de poder que se desenvolvem em determinados espaços. O pensador camaronês se interroga: "Essa noção de biopoder é suficiente para contabilizar as formas contemporâneas em que o político, por meio da guerra, da resistência ou da luta contra o terror, faz do assassinato do inimigo seu objetivo primeiro e absoluto? A guerra afinal, é tanto um meio de alcançar a soberania como uma forma de exercer o direito de matar. Se consideramos a política uma forma de guerra, devemos perguntar: que lugar é dado à vida, à morte e ao corpo humano (em especial o corpo ferido ou massacrado)? Como eles estão inscritos na ordem do poder?" (MBEMBE, 2018, p. 06-07).

${ }_{19}$ Para Foucault, o chamado biopoder é uma tecnologia de poder que procura estabelecer a homeostase interna da população, buscando a segurança do conjunto em relação aos seus perigos internos. Nesse sentido ela é uma tecnologia de previdência ou regulamentadora, operando no nível da massa. Esse poder age para intervir na vida, para fazer viver, na maneira de viver e no "como" fazer viver. A função desse poder seria a de aumentar, estender, prolongar a vida. É importante notar que o poder de que se fala não recai sobre a morte. O biopoder incide sobre a mortalidade e não sobre a morte. A morte "vai ser o momento em que o indivíduo escapa a qualquer poder, pois o poder já não conhece a morte, o poder a deixa de lado" (FOUCAULT, 2010, p. 208).

${ }^{20}$ Sobre o conceito de estado de exceção, Mbembe explicita claramente sua fonte: o jurista alemão Carl Schmitt. Concordando com Schmitt, o filósofo italiano Giorgio Agamben, em o Estado de exceção (2004), diz que o soberano é aquele que suspende o direito, a regra, a lei vigente. O soberano é aquele que pode fazer uso da exceção, que não segue a regra e que suspende o que é de direito, inclusive o próprio direito. O soberano decide sobre o estado de exceção. O estado de exceção cria uma espécie de "não-lugar", onde o sistema jurídico vigente e instituído regularmente é suspenso e passa-se a "governar" a partir de normas ou atos normativos que tem "força de lei". Esses atos normativos com "força de lei" encontram-se em uma situação hibrida, pois estão incluídos no ordenamento jurídico, mas também na forma de exclusão. Assim o soberano está, ao mesmo tempo, dentro e fora do ordenamento jurídico. Segundo Agamben: o que caracteriza propriamente a exceção é que aquilo que é excluído não está, por causa disto, absolutamente fora de relação com a norma; ao contrário, esta se mantém em relação com aquela na forma da suspensão (AGAMBEN, 2004, p. 24). E o filósofo italiano continua: a situação, que vem a ser criada na exceção, possui, portanto, este particular, o de não poder ser definida nem como uma situação de fato, nem como uma situação de direito, mas institui entre estas um paradoxal limiar de indiferença. Não é um fato, porque é criado apenas pela suspensão da norma; mas pela mesma razão, não é nem ao menos um caso jurídico, ainda que abra a possibilidade de vigência da lei (AGAMBEN, 2004, p. 25). Essa instância de não-direito ou de suspensão do direito é analisada por Giorgio Agamben com o objetivo de demonstrar, a partir do estado de exceção discutido por Carl Schmitt, a estratégia acionada pelo direito para salvaguardar (ou garantir) a ordem jurídica. Essa estratégia seria a "força de lei", que, enquanto termo técnico do direito, permite operar uma separação (segundo Agamben) entre a aplicação da norma e o que é formalizado em "sua essência", motivo pelo qual "decretos, disposições e medidas, que não são formalmente leis, adquirem, entretanto, sua 'força de lei'”. É por isso que Agamben, se interrogando sobre o sintagma "força de lei", vai poder afirmar que o estado de exceção é uma força de lei desprovida de lei. O estado de exceção define um "estado de lei" em que, de um lado, a norma está em vigor, mas não se aplica (não tem "força") e, por outro lado, atos que não têm valor de lei adquirem sua "força". Neste caso extremo, a "força de lei" flutua como um elemento indeterminado, que pode ser reivindicado tanto pela autoridade estatal quanto por uma organização revolucionária. O estado de exceção é um espaço anômico em que o que está em jogo é uma
\end{abstract}


e autodeterminação dos povos, mas como uma espécie de tecnologia de poder que transforma determinados espaços políticos em campos de morte, produzindo a "instrumentalização da existência humana e a destruição material de corpos humanos e populações" (MBEMBE, 2018, p. 10-11). Para Mbembe a soberania é uma relação de poder que se constrói segundo a articulação do estado de exceção e a ideia de inimigo para, assim, consolidar o direito de matar. Trata-se, enfim, de uma tecnologia política voltada para a reificação do humano (devirobjeto do ser humano).

A necropolítica está intimamente relacionada com a noção da inimizade. A lógica da inimizade reside nisto: a vida do Outro não é ameaçadora para alguns aspectos da segurança física ou outra forma de segurança, ela é uma ameaça à vida completamente. A eliminação física do outro torna-se a abordagem necessária para tal ameaça percebida, colocando-se em marcha um processo generalizado de distribuição de morte.

Como uma tecnologia voltada para o trabalho de morte (centrada no direito de morte do soberano), a necropolítica, como é bem colocada por Mbembe, não designa uma tecnologia anterior ou posterior à biopolítica. Ela é uma tecnologia política que atravessa todo o processo histórico da Modernidade, permanecendo muitas vezes ocultada, mas sempre em constante tensionamento com as formas biopolíticas. Por esse motivo, Mbembe (2018, p. 27) diz que "qualquer relato histórico do surgimento do terror moderno precisa tratar da escravidão, que pode ser considerada uma das primeiras manifestações da experimentação biopolítica".

A partir da experiência colonial na África (mas que também pode se estender para outros lugares onde se deu o processo de colonização, tal como o continente sul-americano ${ }^{21}$ )

força de lei sem lei... algo como um elemento místico, ou melhor, uma ficção por meio da qual o direito busca se
atribuir sua própria anomia (AGAMBEN, 2004, p. 60-61). Mbembe vê nesse conceito de Agamben uma
metáfora para os campos de morte, que representam a violência destrutiva e soberana, como último sinal do
poder absoluto do negativo. E assim Mbembe $(2018$, p. 8) ressalta: na estrutura político-jurídica do campo, o
estado de exceção deixa de ser uma suspensão temporal do estado de direito. De acordo com Agamben, ele
adquire um arranjo especial permanente, que se mantém continuamente fora do estado normal da lei.
${ }^{21}$ Sobre a experiência colonial no Brasil, Caio Prado Jr. afirma que a escravidão, tal como ocorreu na América,
notadamente no Brasil, possuiu aspectos especialmente negativos. A escravidão no Brasil incorporou de pronto
culturas completamente heterogêneas, sendo uma raça considerada bárbara e outra superior e dominadora. Nesse
processo, diz o historiador, os índios, por meio da obra missionária dos jesuítas, em que pese todos os problemas,
foram afastados das formas mais deprimentes da escravidão. Sobre os negros, Caio Prado destaca: mas para o
negro africano nada disso ocorreu. As ordens religiosas, solícitas em defender o índio, foram as primeiras a
aceitar, a promover mesmo a escravidão africana, a fim de que os colonos, necessitados de escravos, lhes
deixassem livres os movimentos do setor indígena. O negro não teve no Brasil a proteção de ninguém.
Verdadeiro "pária" social, nenhum gesto se esboçou a seu favor. E se é certo que os costumes e a própria
legislação foram com relação a ele mais benignos na sua brutalidade escravista que em outras colônias
americanas, tal não impediu contudo que o negro fosse aqui tratado como o último dos descasos no que diz
respeito à formação moral e intelectual, e preparação para a sociedade em que à força o incluíram. [...] As raças 
Mbembe observa que naquele momento histórico existia uma espécie de poder diferenciado, que intervinha para manter o controle e administrar as populações colonizadas. A experiência colonial permitiu a Mbembe vislumbrar no sistema de plantation europeu verdadeiros espaços de morte. No sistema de plantation Mbembe enxerga a figura do estado de exceção, com todos os seus consectários lógicos: suspensão do ordenamento jurídico, subtração da condição política do homem e o governo exercido por meio da "força de lei". Ao ser levada ao extremo, a lógica do estado de exceção pode levar à subtração do estatuto jurídico e reduzir a condição humana a simples corpos biológicos. Vale lembrar que no sistema de plantation, ou mesmo no sistema escravocrata em geral, o escravo perde a condição humana para se tornar uma coisa (o que outrora foi denominado de "devir-objeto").

$\mathrm{Na}$ colônia, o direito de matar do soberano era irrestrito ${ }^{22}$. De outro lado, a vida do escravo pertencia ao senhor. A vida do escravo, de certo modo, é uma morte em vida. A vida do escravo equipara-se a um objeto, a uma coisa. Essa dominação do escravo é levada a cabo com a perda de seu lar, o afastamento da família, a perda do direito sobre seu corpo e a destituição de todo o status político. Mbembe (2018, p. 28-29) explica que

Como instrumento de trabalho, o escravo tem um preço. Como propriedade, tem um
valor. Seu trabalho responde a uma necessidade e é utilizado. O escravo, por
conseguinte, é mantido vivo, mas em "estado de injúria", em um mundo espectral de
horrores, crueldade e profanidade intensos. [...] Violência, aqui, torna-se um
componente da etiqueta, como dar chicotadas ou tirar a vida do escravo: um
capricho ou um ato de pura destruição visando incutir o terror. A vida do escravo,
em muitos aspectos, é uma forma de morte-em-vida.

Se notamos a morte se tornar o centro da tecnologia política nos regimes de colonização instaurados em diversos lugares do mundo, Mbembe destaca que no regime de apartheid $^{23}$ aparece uma forma peculiar de terror, que na sua essência orquestra o biopoder, o

escravizadas e assim incluídas na sociedade colonial, mal preparadas e adaptadas, vão formar nela um corpo estranho e incômodo. O processo de sua absorção se prolongará até os nossos dias, e está longe de terminado (PRADO JR., 2011, p. 292-293). Quanto ao estatuto jurídico do escravo no Brasil, o historiador explica que "a colônia acompanhou neste terreno o direito romano, para quem o escravo é uma "coisa" do seu senhor, que dela dispõe como melhor lhe aprouver (PRADO JR., 2011, p. 294).

22 Como Mbembe (2018, p. 36) ressalta: "o direito soberano de matar não está sujeito a qualquer regra nas colônias. Lá, o soberano pode matar a qualquer momento ou de qualquer maneira. Diferente do poder soberano antigo onde se exigia uma liturgia para as práticas de morte (os suplícios, por exemplo), na necropolítica a morte é irrestrita e desritualizada. A guerra colonial não está sujeita a normas legais e institucionais. Não é uma atividade codificada legalmente. Em vez disso, o terror colonial se entrelaça constantemente com um imaginário colonialista, caracterizado por terras selvagens, morte e ficções que criam o efeito de verdade".

${ }^{23}$ Mbembe (2018, p. 39) explica que no regime do apartheid na África a soberania era traduzida em ocupação, relegando o colonizado a uma terceira zona, entre o estatuto de sujeito e objeto. Assim, por meio da demarcação 
estado de exceção e o estado de sítio. Para Mbembe, no âmago desse sistema implantado pelos europeus opera o racismo como tecnologia de poder, traduzido na proibição de casamentos mistos, esterilização forçada e extermínios dos povos vencidos.

Diante desse panorama não é difícil concluir que para Mbembe o racismo de estado ${ }^{24}$ aparece durante o processo de colonização europeu ocorrido na Modernidade. Esse processo não só contou com a sistemática escravidão do povo africano, mas também com o extermínio massivo da população indígena na América Latina e, de modo mais particular, como os negros escravizados aqui no Brasil. Por isso, para Mbembe

\begin{abstract}
pouco importa que as tecnologias que culminaram no nazismo tenham sua origem na plantation ou na colônia, ou, pelo contrário - a tese foucaultiana -, que nazismo e stalinismo não tenham feito mais do que ampliar uma série de mecanismos que já existiam nas formações sociais e políticas da Europa ocidental, (subjugação do corpo, eugenia, teorias médico-legais sobre hereditariedade, degeneração e raça). Um traço persiste evidente: no pensamento filosófico moderno assim como na prática e no imaginário político europeu, a colônia representa o lugar em que a soberania consiste fundamentalmente no exercício de um poder à margem de lei $(a b$ legibus solutus) e no qual a "paz" tende a assumir o rosto de uma "guerra sem fim". (MBEMBE, 2018, p. 32-33).
\end{abstract}

Em suma, no contexto da tecnologia necropolítica e da colonização ${ }^{25}$, o direito do soberano, substancializado na forma de morte, consiste basicamente em decidir quem importa ou quem não importa viver. Na dimensão desse poder que tem a morte no seu âmago, há vidas que merecem ser vividas e existem vidas que não são dignas de viver. A soberania é justamente esse poder de decisão sobre a morte. Ela é uma decisão sobre a dignidade ou não de vida.

No cenário político contemporâneo, Mbembe comenta que o direito soberano de matar já não é mais monopólio do Estado. Nesse sentido, Mbembe destaca que uma mudança

espacial o fluxo de mão de obra migrante poderia ser regulamentado e a urbanização africana mantida sob controle.

${ }^{24} \mathrm{O}$ grande traço peculiar do racismo de Estado reside no fato de que ele está vinculado aos mecanismos tecnológicos de poder. O que caracteriza o racismo moderno não é seu caráter ideológico. Nesse sentido, o racismo se caracteriza como a única condição de possibilidade de eliminar a vida em uma sociedade de normalização. O racismo, diz Foucault, "assegura a função de morte na economia do biopoder, segundo o princípio de que a morte dos outros é o fortalecimento biológico da própria pessoa na medida em que ela é membro da raça ou de uma população, na medida em que se é elemento numa pluralidade unitária e viva" (FOUCAULT, 2010, p. 217).

${ }^{25}$ No cenário político contemporâneo Mbembe menciona a ocupação da Palestina como um caso de ocupação colonial moderna, que necessariamente congrega vários poderes: disciplinar, biopolítico e necropolítico. Essa afirmação de Mbembe vem ao encontro da tese que aqui defendemos: para uma análise das relações de poder é imprescindível o auxílio de uma leitura geopolítica. Isso porque é preciso considerar não só a historicidade das práticas de poder, mas também espacialidade a partir da qual elas se desenvolvem. Somado a isso, defendemos que em determinada espacialidade diversas práticas de poder podem atuar simultaneamente sobre diferentes objetos, com finalidades distintas e operando em diversos níveis e cadeias múltiplas de ação. 
econômica na África no último quarto do século XX levou muitos Estados africanos a perderem o monopólio da violência dentro dos seus territórios. O monopólio do poderio bélico, antes pertencente ao Estado, tornou-se um verdadeiro mercado, que oferece armas e mão de obra militar para o comércio. Como resultado disso, houve a formação de exércitos privados, grupos de segurança privada, milícias, grupos paramilitares, todos reivindicando o direito de exercer a violência ou o direito de morte. Cabe ressaltar aqui que de modo similar enfrentamos esses problemas no Brasil, com as facções criminosas responsáveis pelo tráfico de drogas em determinadas localidades, bem como o crescente domínio territorial de milícias $^{26}$. Esses são apenas alguns exemplos de grupos constituídos à margem do Estado e que proclamam o direito de governar sobre seus domínios territoriais, exercendo o direito de violência e morte.

Essas organizações, diz Mbembe, operam como "máquinas de guerra", ou seja, grupos segmentados, constituídos por homens armados, que se dividem e se mesclam em suas atuações, formando corpos difusos e polimorfos. Essas máquinas possuem uma organização política e a estrutura de uma empresa comercial. Elas são organismos predatórios que "taxam territórios e as populações que os ocupam e se baseiam numa variedade de redes transnacionais e diásporas que os proveem com apoio material e financeiro" (MBEMBE, 2018, p. 58).

\section{CONCLUSÃO}

Com a pesquisa de Mbembe podemos notar que o conceito de biopolítica foucaultiano é insuficiente para dar conta das formas contemporâneas de submissão da vida ao poder da morte. Em algumas espacialidades o poder de morte subjuga a vida para além do racismo de Estado pensado por Foucault. Se, de um lado, Foucault enxergou na experiência do nazismo e do socialismo um paradoxo biopolítico; por outro lado, desde o processo de colonização europeia na Modernidade, a necropolítica operou por meios de estados de exceção, disseminação da morte, da dor, do terror e do sacrifício.

\footnotetext{
${ }^{26}$ A autora Ariadna Estévez, no texto Biopolítica y necropolítica ¿constitutivos u opuestos?, nos diz que "as milícias urbanas, os exércitos privados e as polícias de segurança privada também têm acesso às técnicas e práticas de morte. A proliferação de entidades necroempoderadas, junto com o acesso generalizado a tecnologias sofisticadas de destruição e as consequências das políticas socioeconômicas neoliberais, fazem com que os campos de concentração, os guetos e as plantações se convertam em aparatos disciplinares dispensáveis porque são facilmente substituídos pelo massacre, uma tecnologia do necropoder que pode executar-se em qualquer lugar e a qualquer momento (ESTÉVEZ, 2018, p. 19-20, tradução nossa).
} 
A necropolítica é, ainda, uma técnica de poder que está presente na era da governamentalidade neoliberal. Obviamente, ela se manifesta nas zonas periféricas do neoliberalismo, fora do circuito das grandes potências econômicas do planeta. Nessas zonas periféricas, a necropolítica, em tensionamento com outras técnicas de poder, se traduz no crescente aumento das práticas discriminatórias, no vertiginoso aumento dos discursos de ódio, nos grandes extermínios étnicos ocorridos em várias partes do mundo, nos expurgos em massa de determinadas populações do globo, no aumento do número de assentamentos de refugiados. Nesses verdadeiros espaços de morte, "as armas de fogo são dispostas com o objetivo de provocar a destruição máxima de pessoas e criar 'mundos de morte"” (MBEMBE, 2018, p. 71).

Desse modo, ao colher os proveitos das pesquisas de Mbembe, nós sustentamos que a governamentalidade neoliberal abriga duas espécies de técnicas de poder (biopolítica e necropolítica), que em determinados espaços se mostram em constante tensionamento. Assim, podemos dizer que a biopolítica é proeminente nas regiões do globo onde a governamentalidade neoliberal eleva e otimiza as condições de vida. Por óbvio, estamos falando das regiões do planeta que se apresentam como as economias mais fortes e que são capazes de fornecer um "bom estilo de vida" para os indivíduos.

Por outro lado, em regiões do planeta como a África e América do Sul, é possível vislumbrar a existência de localidades, territórios ou espaços em que a regulação da vida é feita pela morte. Nesses continentes se verifica o abandono sistemático de políticas públicas ligadas à saúde, higiene, saneamento básico e à formação de capital humano. Em determinadas localidades a regulamentação da vida se faz por meio de máquinas de guerra (nos moldes citados por Mbembe), que atuam segundo o imaginário do inimigo e preconizam um verdadeiro mundo de morte. As subjetividades produzidas nesses espaços ficam sujeitas à morte sob um duplo aspecto: o real, dividido pelos conflitos armados, pobreza extrema e a submissão a todo tipo de doença e, ainda, a morte simbólica, pois são subjetividades consideradas invisíveis no sentido político e social.

Devemos admitir que a categoria analítica da necropolítica dificulta o posicionamento epistemológico do racismo de Estado pensado por Foucault. Segundo nossa compreensão, o racismo de Estado deve ser inscrito no registro da governamentalidade neoliberal e visualizado a partir de práticas que promovam clivagens sociais a partir da noção de biopolítica. Obviamente, nesse novo cenário, há um novo sentido para o "fazer viver e deixar morrer". O racismo pode provocar um corte no corpo da sociedade (neoliberal) simplesmente 
pela distinção das subjetividades que são potencialmente mais aptas a "capitalizar" seu capital humano. Isso não impede que os antigos conflitos étnico-raciais, culturais e de gênero sejam reinscritos na fórmula do neoliberalismo.

Entretanto, vemos que em determinadas regiões do mundo o poder político é regulado pela morte. A soberania representa o direito de escolher quem vai viver e quem deve morrer. Assim, a biopolítica, e mesmo o racismo de Estado, são categorias insuficientes para explicar algumas realidades em que não se deseja fazer viver, mas sim fazer morrer ou reificar seres humanos. Em nossa compreensão, é inegável que há na periferia da governamentalidade neoliberal uma forte inclinação para o devir-objeto do humano, enquanto que no epicentro do neoliberalismo existe a articulação de tecnologias governamentais para a produção do "sujeito-capital", o empreendedor do si mesmo.

\section{REFERÊNCIAS}

AGAMBEN, Giorgio. Estado de exceção. Tradução Iraci D. Poleti. São Paulo: Boitempo, 2004.

AGAMBEN, Giorgio. Homo sacer: o poder soberano e a vida nua. Belo Horizonte: Editora UFMG, 2010.

AVELINO, Nildo. Foucault, governamentalidade e neoliberalismo. In: RESENDE, Haroldo (org.). Michel Foucault: política: pensamento e ação. Belo Horizonte: Autêntica, 2016. p. 163-178.

BONNAFOUS-BOUCHER, Maria. Le libéralisme dans la pensée de Michel Foucault: um libéralisme sans liberte. Paris: L`Harmattan, 2001.

CASTRO, Edgardo. Introdução a Foucault. Tradução Beatriz de Almeida Magalhães. Belo Horizonte: Autêntica, 2015.

DELEUZE, Gilles. Post-Scriptum sobre as sociedades de controle. In: DELEUZE, Gilles Conversações. São Paulo: Editora 34, 1992.

ESTÉVEZ, Ariadna. Biopolítica y necropolítica ¿constitutivos u opuestos? Espiral: Estudios sobre Estado y Sociedad, v. 25, n. 73, 2018, p. 9-43.

FOUCAULT, Michel. Ditos e escritos. Arqueologia das ciências e história dos sistemas de pensamento. Organizado por Manoel Barros da Motta. Tradução Elisa Monteiro. 3. ed. Rio de Janeiro: Forense Universitária, 2013. v. II.

FOUCAULT, Michel. Ditos e escritos. Estratégia, poder-saber. Organizado por Manoel Barros da Motta. Tradução Vera Lucia Avellar Ribeiro. 3. ed. Rio de Janeiro: Forense Universitária, 2015(b). v. IV. 
FOUCAULT, Michel. Ditos e escritos. Filosofia, diagnóstico do presente e verdade. Organizado por Manoel Barros da Motta. Tradução Abner Chiquieri. Rio de Janeiro: Forense Universitária, 2014(a). v. X.

FOUCAULT, Michel. Ditos e escritos. Genealogia da ética, subjetividade e sexualidade. Organizado por Manoel Barros da Motta. Tradução Abner Chiquieri. Rio de Janeiro: Forense Universitária, 2014 (b). v. 9.

FOUCAULT, Michel. Em defesa da sociedade: curso no Collège de France (1975-1976). Tradução Maria Ermantina Galvão. São Paulo: Martins Fontes, 2010.

FOUCAULT, Michel. História da sexualidade I: a vontade de saber. Rio de Janeiro, Edições Graal, 1988.

FOUCAULT, Michel. Nascimento da biopolítica: curso dado no Collège de France (19781979). São Paulo: Martins Fontes, 2008(a).

FOUCAULT, Michel. Segurança, território, população: curso dado no Collège de France (1977-1978). São Paulo: Martins Fontes, 2008(b).

FOUCAULT, M. O sujeito e o poder. In: DREYFUS, H. L.; RABINOW, P. Michel

Foucault: uma trajetória filosófica. Para além do estruturalismo e da hermenêutica. 2. ed. Rio de Janeiro: Forense Universitária, 2009. p. 231-249.

LAGASNERIE, Geoffroy. A última lição de Foucault. Tradução André Telles. São Paulo: Três Estrelas, 2013.

LEMKE, Thomas. Foucault, governamentalidade e crítica. Tradução Mario Antunes Marino, Eduardo Altheman Camargo Santos. São Paulo: Editora Filosófica Politeia, 2017.

MBEMBE, Achille. Crítica da razão negra. Tradução Marta Lança. Lisboa: Antígona, 2014.

MBEMBE, Achille. Necropolítica. Biopoder, soberania, estado de exceção, política de morte. Tradução Renata Santini. São Paulo: n-1 edições, 2018.

MBEMBE, Achille. Políticas da inimizade. Tradução Marta Lança. Lisboa: Antígona, 2017.

PRADO JR. Caio. Formação do Brasil contemporâneo. São Paulo: Companhia das Letras, 2011.

TÓTORA, Silvana. Foucault: Biopolítica e governamentalidade neoliberal. REU - Revista de Estudos Universitários, v. 37, n. 2, p. 81-100, 2011.

VALENCIA, Sayak. Capitalismo gore. Editorial Melusina, Santa Cruz de Tenerife, 2010. 